\title{
ECONOMICS OF RECOVERY FOR URBAN PARTICULATE MATTER AND CHEMICALS
}

\author{
JOHN SANSALONE \& SAURABH RAJE \\ Engineering School of Sustainable Infrastructure and Environment, University of Florida, USA
}

\begin{abstract}
Recovery of particulate matter (PM) and PM-associated chemicals (metals, nutrients, organics) deposited in urban drainage (stormwater and/or wastewater) conveyance and treatment systems is reality; often ignored until loss of hydraulic functionality, treatment mis-behavior or system failure requires recovery. Sustainability practices (recovery of PM and chemicals), such as street sweeping (SS), can provide significant economy for PM and PM-associated chemicals such as total phosphorus (TP) and total nitrogen (TN) loads compared to unit operations (nominally, best management practices (BMPs)), before such loads become part of the urban water cycle. Any resulting recovery has potential to significantly reduce PM and chemical loads to the urban drainage cycle and would otherwise directly impact conveyance, treatment and receiving water systems. The primary study objective is to demonstrate that sustainability, through quantified maintenance practices, is economically beneficial based on cost-per-load-recovered. A second objective is examination of maintenance intervals that accounted for PM build-up, washoff and recovery functions for SS, catch basins and BMPs. The methodology of this study was physical sampling from 14 municipal separate storm sewer systems in Florida; over 400 samples of PM $(\sim 2 \mathrm{~kg}$ each $)$ were recovered. Since PM was the vehicle for recovery of TP and TN, these analytes were quantified through laboratory analysis for each sample. Results from across Florida indicate that when SS was used as a serial control strategy in a source area providing runoff to a BMP, an SS interval from 3-15 days with a 6-12-month BMP cleaning interval provided the lowest recovery costs. Nominally, SS-load recovery costs were $\$ 0.10 / \mathrm{kg}(\mathrm{PM}), \$ 250 / \mathrm{kg}$ (TP), $\$ 200 / \mathrm{kg}(\mathrm{TN})$ at a 7 -day SS interval, compared to $\$ 8-12 / \mathrm{kg}$ (PM), $\$ 21,000-33,000 / \mathrm{kg}$ (TP) and $\$ 9,000-$ $13,000 / \mathrm{kg}(\mathrm{TN})$ at a 6-month cleaning interval for BMPs. For any level of recovery or SS efficiency, results indicate that SS manages constituents before transport and partitioning in runoff, which is much more economical than BMP treatment. Extension of these results leads to the recommendation that when combined with BMPs, SS as an upstream control strategy for BMPs improves serial recovery of PM, TP and TN loads for BMP designed to provide volumetric and flow control. Results of this study represent a defensible and quantifiable foundation to build pollutant-load-reduction credits and quantify load-recovery economics.
\end{abstract}

Keywords: urban drainage, sustainability, maintenance, nutrients, load credits, infrastructure, street sweeping.

\section{INTRODUCTION}

For the ecological health of receiving waters, phosphorus $(\mathrm{P})$ and nitrogen $(\mathrm{N})$ are limiting for eutrophication [1]. Eutrophication has been recognized as a common condition for many receiving water systems impacted by urban runoff due to anthropogenic and biogenic generation and mobilization of $\mathrm{N}$ and $\mathrm{P}$ at elevated concentrations and loadings [2]-[6]. Urban runoff is recognized as significant nonpoint source of $\mathrm{N}$ and $\mathrm{P}$ as well as inorganic and organic PM [7], [8]. With demographic changes, land use and anthropogenic activities, runoff impacts are increasing [9]. For example, a number of decades ago Smith et al. [10] demonstrated that $48 \%$ of 410 water chemistry monitoring sites did not meet a widelyaccepted USEPA level of $0.10 \mathrm{mg} / \mathrm{L}$ at that time, as total P (TP). An impact of eutrophication and PM delivery is oxygen depletion (anoxic or anaerobic conditions) in urban drainage appurtenances such as catch basins (CBs), unmaintained best management practices (BMPs) such as wet vaults or hydrodynamic separators, or BMPs with wet sumps and ultimately in 
receiving waters. This is particularly problematic for BMPs that are not maintained and cleaned on a frequent basis (in terms of months). Such impairments impact aesthetics, ecology and water use designations [11]. Eutrophication imposes a high economic, environmental, ecological, and human health cost [12].

Loads of nutrients, metals, pathogens and PM are generated and transported through the combination of anthropogenic activities, biogenic sources and the altered rainfall-runoff relationships generated from urban infrastructure imposed on the hydrologic cycle. For example, specific urban land use designs such as grassed and vegetated areas with runon to impervious pavement are identified as significant sources of biogenic P [6]. Anthropogenic sources of $\mathrm{P}$ besides fertilizer include P-based admixtures, for example phosphogypsum in concrete, released from the pavement during abrasion and weathering [13], and irrigation with reclaimed wastewater. $\mathrm{N}$ and $\mathrm{P}$ are introduced to the aquatic environment in different chemical forms, but nominally partition between aqueous and PM phases [14]. In addition to a simple two-component partitioning between dissolved and particulate phases, $\mathrm{N}$ and $\mathrm{P}$ partition to and distribute across PM sizes transported in runoff [15]. Knowledge of PMbased $\mathrm{N}$ and $\mathrm{P}$ loads is needed to evaluate source control, fate, treatment mechanisms and municipal separate storm sewer system (MS4) maintenance practices [14].

While low impact development practices (LID) at the parcel or catchment-level often are increasingly used for urban land uses providing hydrologic restoration and therefore load reduction, structural unit operations (BMPs are unit operations and processes) such as wet and dry basins, vaults, or manufactured systems such as hydrodynamic separators continue to be most commonly applied. Without frequent maintenance viable performance of such units for nutrient reduction is not sustainable. Even with frequent maintenance for many of these unit operations, the control of dissolved and suspended $\mathrm{N}$ and $\mathrm{P}$ has been much less effective compared to separation of coarser sediment-size $(>75 \mu \mathrm{m}) \mathrm{PM}$-bound $\mathrm{N}$ and $\mathrm{P}$ through sedimentation mechanisms and physical filtration for the finer settleable/suspended fractions $(<75 \mu \mathrm{m})$ [16], [17]. During inter-event storage of PM, gross solids, and runoff in stormwater appurtenances and BMPs, coupled redox and $\mathrm{pH}$ changes occur. The speciation, partitioning and distribution of $\mathrm{P}$ are relatively stable as compared to $\mathrm{N}$. Approximately onethird of $\mathrm{P}$ in source area runoff is dissolved and PM-based $\mathrm{P}$ typically ranges from 0.01 to $10 \mathrm{mg} / \mathrm{g}$ with the highest concentration values for suspended and lowest for coarse sediment $\mathrm{PM}$, noting that the predominance of the runoff PM mass is sediment-size or coarser and therefore so are TP and TN loads.. Source area N is approximately $40 \%$ dissolved and can be biologically-mediated under anaerobic redox conditions. The highest PM-based values are associated with suspended PM depending on the biogenic PM fraction [6]. One of the major concerns with small footprint BMPs such as vaults, tanks and screened hydrodynamic separators is scour of PM and associated nutrients. Maintenance not only has the potential to provide load credits but irrespective of load credits will always benefit in the intended unit design or behavior. For this study of $14 \mathrm{MS} 4 \mathrm{~s}$ across Florida that included collection and analysis of over 400 samples there are two study objectives. The first is to demonstrate the economy of maintenance practices based on cost per load recovered. The second objective is examination of maintenance intervals that accounted for PM build-up, washoff and recovery functions for street sweeping (SS), CB and BMPs.

\section{BACKGROUND}

In the United States of America (USA), Total Maximum Daily Loads (TMDL) and their associated allocations often are based on watershed-scale estimations or modeling evaluations of constituent loads, for example, N, P and PM. Providing an accurate and precise assessment of an anticipated load reduction from stormwater program activities and BMPs is 
a formidable task for any municipal separate storm sewer system (MS4). Because of the financial ramifications of meeting TMDL load reduction allocations, tools are needed to provide more scientifically accurate estimates of loads and load reductions by BMPs or source control practices. Additionally, an MS4 consisting of drainage systems, drainage appurtenances and BMPs will "inventory" a significant load of constituents. Within an MS4 this load distribution begins with source areas such as pavement and ends at the point of discharge to the receiving system.

Conceptually, a TMDL is easily understood. However, quantification of current stormwater loadings from an MS4 requires knowledge of the individual hydrologic functional units (HFU) that make up an MS4 system or a watershed. Individual HFUs in an MS4 include for example, a contiguous unit area of pavement that drains to the same catch basin or BMP within a given land use, a single catch basin or a relatively hydrologicallyhomogeneous landscaped area. Such HFUs are examples of the basic building blocks of an MS4 system or an urban watershed. These are a few HFU examples of the building blocks in an MS4 serving as pollutant sources and sinks and can represent components of an urban hydrologic model for pollutant load build-up/wash-off or transport/fate. In an MS4 or urban watershed these three HFUs illustrated are commonly interconnected hydrologically and hydraulically. For example, paved or landscaped source areas drain to catch basins which are hydraulically connected to BMPs. Such information provides important potential sources of constituent loading, beginning with traffic deposition and runon for impervious pavement, drainage appurtenances such as catch basins, and BMPs. While each HFU is a potential sink for constituents, each HFU is a potential source if not maintained. While on an individual HFU-basis the loads are small compared to a watershed-scale load, the number of these HFU of a specific type is very large for an MS4.

As a result, most MS4s have potentially significant and non-stationary load inventories within these HFUs that require quantification and management (maintenance, cleaning, and recovery). The recovery of these materials is rarely (if ever) defensibly quantified to illustrate the potential load reduction that may be carried out expeditiously by an MS4 through maintenance practices. It is noted that at a larger scale nearly all TMDLs are based on calculation and not load measurement. Furthermore, in the absence of such load management, these HFU load sinks become potential acute and chronic constituent load sources in which constituents otherwise associated with a less mobile particulate phase are leached, becoming mobile soluble pollutant loads that most downstream BMPs are incapable of treating and retaining to a significant extent. While the focus of this paper is nutrients and PM, toxics, pathogens and ubiquitous chemical classes such as endocrine disruptors and biocides also require similar management and maintenance strategies.

The authors are not aware of previous studies, whether nationally, regionally or MS4 specific, that have focused on an examination of nutrients associated with PM that accumulate on urban surfaces (pavement) and is recovered by street cleaning, in drainage systems and appurtenances and in BMPs which are effective in separating coarse PM and associated nutrients. This study provided Florida-based information and guidance beyond analogs to the site or specific conditions of the land use or BMP. To date there have been no Florida previous studies that could be identified by the authors that provide a tool, metric or yardstick to relate PM mass recovered by typical MS4 maintenance practices, to nutrient mass. In this study, the metrics were based on data collection across the state of Florida in the USA. This project generated results for Florida MS4s that is currently not available and is needed since MS4s are faced with quantifying load reductions in MS4 permits and Basin Management Action Plans (BMAP) to achieve TMDLs. In addition to a consistent sampling/analysis methodology the statistical (or probabilistic) analysis of results from 
Florida MS4 studies is the key component to any potential quantitative analysis of nutrient load reductions resulting from MS4 management/maintenance practices. However, the methods must be robust, representative and defensible. In order to obtain representative values of nutrient loading or reduction in this tabular loading framework (for example, $\mathrm{P}$ loadings in street sweepings from residential land use pavements) it is necessary for an MS4 to collect replicate samples. For example, samples obtained by the Florida MS4s in a particular category (for example, TP loading in street sweepings from residential land use pavements) were in sufficient number so that statistics such as the mean, median, standard deviation, quartiles and range levels such as a 95th or 5th percentile level can be provided. The metric for these results is a non-parametric form (without relying on analysis based on a probabilistic distribution) as "box and whisker" plots or in many cases probabilistic distributions.

Based on previous results for recovery of urban residuals from BMPs and recovered urban PM inventories [18], results demonstrated relationships between dry mass of recovered PM and metal mass $(\mathrm{Cd}, \mathrm{Cu}, \mathrm{Pb}, \mathrm{Zn})$. In this study, PM mass is utilized as an economical index instead of the more appropriate (but less economical) granulometry measure of PM surface area. From these previous results, this study quantifies the relationship between dry mass of residuals and nutrients [13], [14], [17].

From analysis of these MS4 sets of Florida-based data an MS4 can convert dry mass of residual PM recovered to mass of nutrients recovered. As a result of the study, a Floridabased metric developed from this study allows an MS4 to quantify N and P mass recovered from dry PM mass recovered without requiring $\mathrm{N}$ and $\mathrm{P}$ analysis for each maintenance operation undertaken by a MS4. Recognizing that the relationships between dried PM mass that is recovered to $\mathrm{N}$ or $\mathrm{P}$ mass has a distribution range there is a range of levels that load credits can be apportioned, for example at a quartile such as the 25th, 50th (median and in many cases the representative statistic or the resulting distributions), 75 th, or at another chosen level.

\section{METHODOLOGY}

The nutrient and PM transport path in urban drainage in a common urban HFU configuration is from source areas (in this study, pavement) to drainage appurtenance (in this study, catch basins), to drainage conveyance system, to a BMP (representative of the BMP commonly deployed and maintained by an MS4 in this study), with discharge to the stormwater system or receiving water. For perspective, Fig. 1 illustrates the MS4s and roadway network around Florida. Potential recipients of nutrient loadings from the HFUs are both fresh and saltwater receiving waters down-gradient of stormwater system discharges. In Florida many primary receiving waters are proximate to the MS4s of this study. Hence, providing load credits for regular maintenance and cleaning practices has a positive impact on HFU performance and beneficial impacts to receiving waters.

Many MS4s in this study are in areas with more than 30\% imperviousness. Highly impervious areas generate increased runoff (altered rainfall-runoff relationships), PM, metals, nutrients and emerging chemicals ultimately resulting in the potential for such urban inventory to generate higher loads to receiving waters. While urban generation and transport of load is not solely or linearly a function of imperviousness, imperviousness is an index that can be tied directly to hydrologic and hydraulic modification as well as anthropogenic activities and design, resulting in increased loads. Hydrologic alterations drive load through altered characteristics of the hydrograph. Increased imperviousness has a demonstrable impact on the three primary attributes of a hydrograph: peak, volume and temporal 


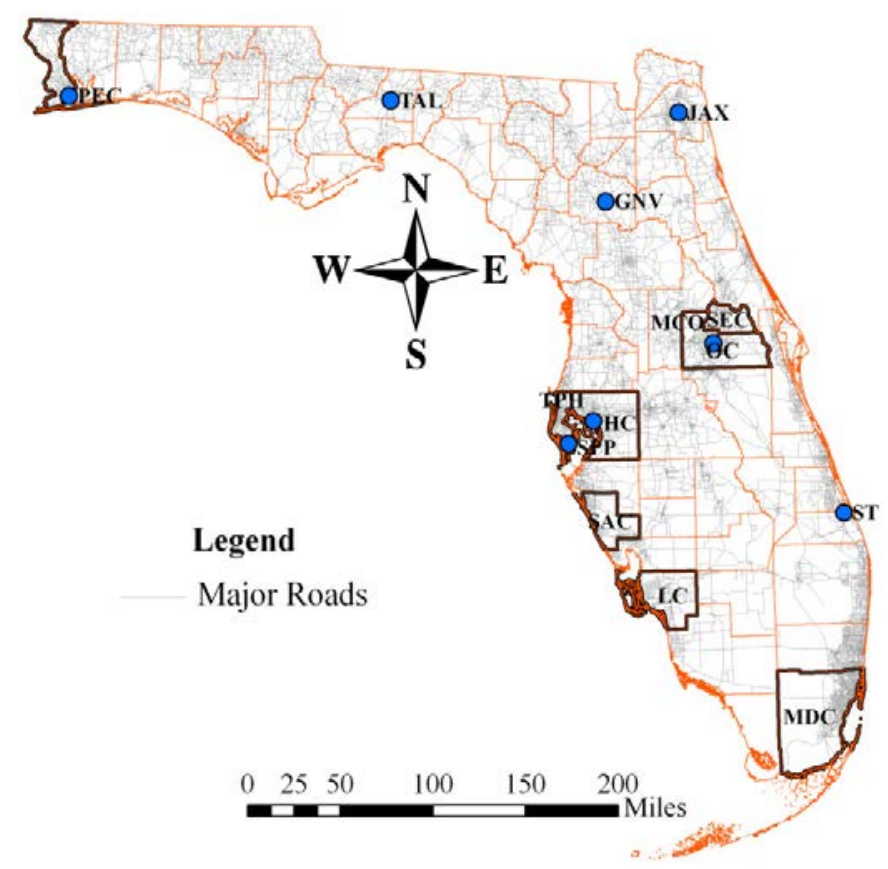

Figure 1: MS4 nomenclature, resulting TP and TN distribution of MS4 sampling locations with major roads overlaid across Florida.

Table 1: $14 \mathrm{MS} 4 \mathrm{~s}$ with resulting TP and TN results.

\begin{tabular}{lcc}
\hline \multicolumn{1}{c}{ MS4 } & $\begin{array}{c}\mathrm{TP} \\
{[\mathrm{mg} / \mathrm{kg}]}\end{array}$ & $\begin{array}{c}\mathrm{TN} \\
{[\mathrm{mg} / \mathrm{kg}]}\end{array}$ \\
\hline Gainesville (GNV) & 325.6 & 319.4 \\
Hillsborough County (HC) & 384.3 & 360.1 \\
Jacksonville (JAX) & 304.1 & 430.4 \\
Lee County (LC) & 407.5 & 483.6 \\
Miami-Dade County (MDC) & 735.0 & 1129.7 \\
Orange County (OC) & 288.9 & 595.8 \\
Orlando (MCO) & 552.5 & 1659.8 \\
Pensacola/Escambia County (PEC) & 96.2 & 419.1 \\
Sarasota County (SAC) & 969.0 & 648.5 \\
Seminole County (SEC) & 350.5 & 1229.8 \\
St. Petersburg/Pinellas County (SPP) & 249.1 & 614.2 \\
Stuart (ST) & 286.7 & 814.8 \\
Tallahassee (TAL) & 506.2 & 1219.5 \\
Tampa (TPH) & 388.1 & 771.1 \\
\hline
\end{tabular}


attenuation. The $14 \mathrm{MS} 4 \mathrm{~s}$ are listed in Table 1 with resulting TP and TN results and Fig. 1 illustrates the distribution of the MS4s across Florida.

Each MS4 collected 27 PM-based samples that were pooled in a Florida-based analysis. Samples were collected from 3 different HFUs within 3 different land uses; highway $(\mathrm{H})$, commercial (C) and residential (R). HFUs include street sweeping, catch basins and BMPs. The BMPs that each MS4 maintain most frequently were included in the sampling by an MS4. For each HFU in a land use, samples were collected from 3 different locations. Each MS4 was responsible for cleaning and providing all the sampling equipment. The street sweepers required cleaning with potable water prior to sweeping the sampling area. Detailed information for each location was provided in the field information submitted by the MS4s for each sample collected. After collection, the samples were stored on ice until receipt at University of Florida in GNV. All wet or moist samples were immediately refrigerated. All laboratory analyses were conducted by the University of Florida laboratories. Sub-samples were generated from each sample and analyzed for PM, TP and TN.

\section{RESULTS}

For each of eleven (11) MS4s, samples were obtained under conditions where there was no known reclaimed wastewater impacting the hydrologic functional unit (HFU) and land use locations of the samples. For the $11 \mathrm{MS} 4 \mathrm{~s}$ twenty seven (27) samples from three hydrologic functional units (HFU) were obtained. HFUs consisted of a planned variety of best management practices (BMPs) most frequently maintained by the MS4, paved area street sweepings (SS), and catch basins (CBs). HFUs were sampled for three land uses: highway $(\mathrm{H})$, commercial $(\mathrm{C})$ and residential $(\mathrm{R})$. For each sampling matrix category, three independent locations were utilized.

Results from this effort is categorized in terms of HFU and land use for nitrogen ( $\mathrm{N}$, as $\mathrm{TN}$ ), phosphorus (P, as TP) and PM. This study was designed to create a Florida-based metric for TN and TP. This study was not designed to compare and contrast results for individual MS4s or between classes of BMPs. Germaine to this study, it is noted that the results presented are a function of many variables, and while BMP vendors promote differences between BMPs the reality is that such treatment and cost differences are rarely if ever statistically or practically significant given a lack of BMP maintenance, the variability of actual hydrologic loadings, and the benefits of urban maintenance practices. While the Florida-based results indicate differences between HFUs and between land uses, results consistently indicates that the metrics of TN and TP are log-normally distributed. This observation is important for allocation of load credits because the results are not represented by a singular concentration $(\mathrm{mg} / \mathrm{kg})$ but by log-normal distributions thereof whether examined based on HFU categories or land use categories as lumped together for the entire state of Florida. While a number of statistical indices could be selected (mean, median, 25th, 75th quartiles) the consistent log-normality of results leads to the use of a median (50th percentile) concentration $(\mathrm{mg} / \mathrm{kg})$ from each distribution. It is recommended that the metric or yardstick by which dry mass equivalent of PM recovered is equated to TN and TP be based on the median value from the Florida-based distributions (either as a function of land use or with all land uses combined). Table 2 summarizes these Florida-based results as a function of HFU and land use outside MS4 areas loaded by reclaimed wastewater. These tabular results represent the $\mathrm{mg}$ of $\mathrm{TN}$ or $\mathrm{TP}$ per equivalent dry $\mathrm{kg}$ of $\mathrm{PM}$ and/or gross solids recovered by a maintenance practice, but cannot be construed as an index for BMP treatment effectiveness or "separation or removal efficiency". Based on the numerical value and associated units in the table, the dry kg of urban PM detritus recovered can be converted to $\mathrm{mg}$ of TN or TP recovered by a maintenance practice. 
Table 2: This table represents the Florida-based metrics (yardstick) developed in this study to convert dry PM (and/or gross solids) mass to a PM-based TP or TN in units of [mg of TP or TN per dry mass in kg of PM recovered]. The metrics are presented in the upper part of the table as a function of land use and HFU from PM recovered in this study by maintenance practices (street cleaning, catch basin cleaning, BMP cleaning). The metrics are presented as a median, mean and standard deviations each developed from log-normal distributions. The lower part of the table summarizes the results as a function of HFU irrespective of land use.

\begin{tabular}{|c|ccc|ccc|ccc|}
\hline TP & \multicolumn{3}{|c|}{ Street Sweeping (SS) } & \multicolumn{3}{c|}{ Catch Basin (CB) } & \multicolumn{4}{c|}{ BMP } \\
{$[\mathbf{m g} / \mathbf{k g}]$} & Mean & Median & St. Dev. & Mean & Median & St. Dev. & Mean & Median & St. Dev. \\
\hline $\mathbf{C}$ & 482.6 & 381.2 & 476.9 & 530.9 & 300.8 & 524.9 & 474.6 & 295.7 & 412.6 \\
R & 425.8 & 374.9 & 284.7 & 559.2 & 423.4 & 543.0 & 702.8 & 382.7 & 670.5 \\
H & 622.0 & 349.7 & 778.5 & 566.6 & 536.9 & 363.3 & 759.4 & 513.7 & 972.1 \\
\hline TN & \multicolumn{3}{|c|}{ Street Sweeping (SS) } & \multicolumn{3}{|c|}{ Catch Basin (CB) } & \multicolumn{4}{c|}{ BMP } \\
[mg/kg] & Mean & Median & St. Dev. & Mean & Median & St. Dev. & Mean & Median & St. Dev. \\
\hline C & 789.1 & 429.6 & 944.2 & 1459.7 & 467.2 & 2237.8 & 1999.0 & 602.1 & 3104.1 \\
R & 1439.0 & 832.4 & 2169.9 & 1803.9 & 773.8 & 2955.8 & 3587.7 & 1169.0 & 4991.9 \\
H & 826.6 & 546.4 & 654.8 & 1926.3 & 785.4 & 2587.8 & 2342.4 & 939.2 & 3496.6 \\
\hline
\end{tabular}

\begin{tabular}{|c|ccc|ccc|}
\hline & \multicolumn{3}{|c|}{ TP } & \multicolumn{3}{c|}{ TN } \\
Recovery & \multicolumn{3}{|c|}{$[\mathrm{mg} / \mathrm{kg}]$} & & \\
& Mean & Median & St. Dev. & Mean & Median & St. Dev. \\
\hline Street Sweeping (SS) & 512.5 & 361.0 & 599.9 & 1012.2 & 563.0 & 1422.2 \\
Catch Basin (CB) & 552.2 & 416.8 & 481.8 & 1729.1 & 679.1 & 2601.6 \\
BMP & 647.1 & 363.9 & 728.9 & 2648.1 & 898.5 & 3983.1 \\
\hline
\end{tabular}

These tabular data were also further aggregated into a single Florida-based metric for TP and separately for TN that was irrespective of both land use and HFU. All PM-based TN and TP results across Florida fit log-normal distributions. The lognormal distribution of the results indicates that the representative statistic is the median (the 50th percentile). Given the predominance of the lognormal distributions $(\alpha=0.05)$, results are compared based on the median of the distributions. TP is predominately PM-bound [6]. TP results expressed in [mg of TP/kg of PM] for the $14 \mathrm{MS} 4 \mathrm{~s}$ for all land uses and all HFU locations; as a median value across Florida was $374 \mathrm{mg}$ of TP/kg of PM. N loads are commonly considered in terms of aqueous species either in rainfall or runoff. However urban source areas such as the HFUs of this study can generate total nitrogen (TN) in runoff that is also predominately PM-bound. $\mathrm{TN}$ results expressed in [mg of TN/kg of PM] for the $14 \mathrm{MS} 4 \mathrm{~s}$ for all land uses and all HFU locations; as a median value across Florida is $701 \mathrm{mg}$ of TN/kg of PM. On a Florida basis, 147 dry $\mathrm{kg}$ of PM are recovered per lane-mile swept at $\$ 31$ per lane-mile swept. These values are illustrated graphically in Fig. 2. A summary of the cost $(\$ / \mathrm{lb})$ for BMP treatment as compared to maintenance practices are shown in Table 3.

In Table 3 a BMP treatment train is the practice of passive wet basin sedimentation followed by passive sand filtration. Florida-based BMPs includes a wide diversity of BMPs across Florida from wet basin sedimentation to grassed swales to manufactured BMPs such as screened or baffled hydrodynamic separators. The specific analysis of both classes of hydrodynamic separators is based on $2000 \mathrm{~m}^{2}$ urban catchment draining to a hydrodynamic 

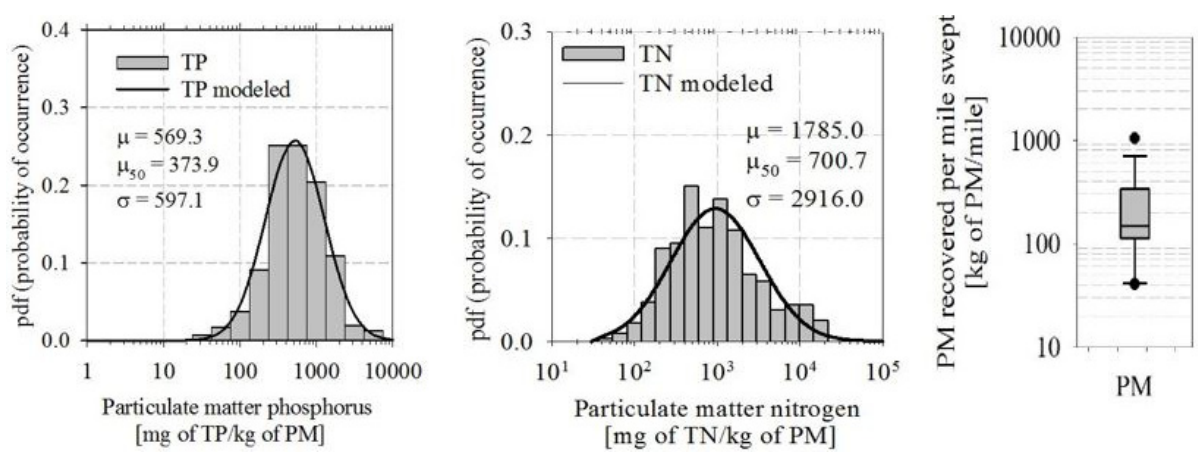

Figure 2: $\quad$ Summary of Florida-based TP and TN distributions as well as PM recovered from street sweeping per lane-mile.

Table 3: Comparison of BMP (treatment) vs. maintenance (recovery) costs in ( $\$ / 1 b)$ for PM, $\mathrm{TP}$ and TN. For BMPs, separation and recovery are required, while only recovery is required for maintenance practices.

\begin{tabular}{|l|ccc|}
\hline \multicolumn{1}{|c|}{ Separation and/or Recovery Method } & \multicolumn{3}{c|}{ Median Cost (\$/lb) } \\
\hline BMP Treatment Train & TN & TP & PM \\
Florida-based BMPs & 935 & 32,600 & 26 \\
Screened Hydrodynamic Separator & 1,900 & 10,500 & 41 \\
& 3,730 & 9,210 & 4 \\
Baffled Hydrodynamic Separator & $(1,280-14,860)$ & $(3,170-36,680)$ & $(1-13)$ \\
Street Sweeping & 3,020 & 7,450 & 3 \\
Catch Basin Cleaning & $(1,280-14,860)$ & $(3,170-36,680)$ & $(1-13)$ \\
& 165 & 257 & 0.10 \\
& 1,016 & 1,656 & 0.70 \\
\hline
\end{tabular}

separator (HS) with 50\% PM annual removal efficiency based on clean sump conditions [19]. This result assumes no scour or washout from the screened hydrodynamic separator in order to compare to other separators. Accounting for scour and washout will result in costs higher than the median costs shown. Finally, the cost for catch basin recovery is based on 100 dry pounds of PM recovery per catch basin based on an annual cleaning frequency.

An example is illustrated that uses, for simplicity, the Florida-based metrics that are independent of land use in the lower part of Table 2. This example is based on recovery or separation/recovery of $1 \mathrm{lb}$ of TP and $1 \mathrm{lb}$ of TN. For street sweeping the median metrics from Figure 2 or the lower part of Table 2 can be combined with median of the PM recovery distribution provided by MS4s from sweeping 1 lane-mile of pavement, 147 dry $\mathrm{kg} \mathrm{PM} / \mathrm{mile}$ swept resulting in $0.12 \mathrm{lb} \mathrm{TP}$ and $0.18 \mathrm{lb} \mathrm{TN}$ recovered. In this example the number of pavement lane-miles that need to be swept (cleaned) to recover $1 \mathrm{lb}$ of TP and TN, are respectively, 8.5 and 5.5 miles. This mass is thereby removed as a potential runoff load. For a catch basin the median TP concentration is $417 \mathrm{mg}$ of TP/kg of PM and for TN is $679 \mathrm{mg}$ of TN/kg of PM. The resulting calculations produce a value of $0.04 \mathrm{lb} \mathrm{TP}$ and $0.07 \mathrm{lb} \mathrm{TN}$ recovery per catch basin per $100 \mathrm{lb}$ of PM recovered. In this example the number of catch basins needed to recover $1.0 \mathrm{lb}$ of TP and TN are 24.0 and 14.7, respectively. For a BMP (using an example of a screened hydrodynamic separator) results in $627 \mathrm{lb}$ of PM (284 kg) 
separated by the BMP annually. By installing this BMP and recovering this mass of PM it is possible to calculate through the values in the lower part of Table 2 the associated TP and TN mass. In particular these values are $363.9 \mathrm{mg} \mathrm{TP} / \mathrm{kg}$ of PM and $898.5 \mathrm{mg} \mathrm{TN} / \mathrm{kg}$ of PM. By multiplying these values by the PM recovered in the BMP results yield $0.23 \mathrm{lb}$ TP and $0.56 \mathrm{lb}$ TN separated for $1 \mathrm{BMP}$ in 1 year. In this example to recover $1.0 \mathrm{lb}$ of TP and TN an MS4 would have to purchase and maintain 4.4 screened HS units and 1.8 screened HS units, respectively on an annual basis while assuming no scour and washout of PM. Separate from the above illustrative example the Florida-based BMPs and maintenance practice costs are summarized in Table 3.

\section{CONCLUSIONS}

Maintenance matters. To demonstrate this statement, this study created a Florida-based set of metrics based on triplicate sampling as a function of land use (residential, commercial and highway) and the common urban hydrologic functional units (HFUs) that collect PM and detritus (pavements - street sweeping, catch basins and best management practices, BMPs) across $14 \mathrm{MS} 4 \mathrm{~s}$ in Florida. Across Florida, 459 samples were collected and analyzed to create this set of Florida-based metrics to provide nutrient load credits for maintenance. For a given land use or HFU this Florida-based metric equates the equivalent dry load of particulate matter (PM) and urban detritus recovered by maintenance to the TN and TP load recovered from this PM and detritus. Recognizing the inherent variability of the results across $14 \mathrm{MS} 4 \mathrm{~s}$ even as a function of HFU and land use, results were consistently represented by a log-normal distribution and as a result the median of the distribution was used in the set of Florida-based metrics. The essence of this study is summarized in Table 2 of Florida-based metrics that relate equivalent dry mass recovered to mass of $\mathrm{TN}$ and $\mathrm{TP}$ as a function of land use and HFU.

In summary, study results reinforces the knowledge that source controls or urban maintenance practices such as street sweeping can be a very cost effective tool in reducing stormwater constituent loads as compared to catchment-based structural BMPs. With respect to the costs of recovery for PM, TP or TN, Table 3 summarizes the costs of street sweeping as compared to other maintenance or treatment practices. Table 3 also compares maintenance practice costs to the costs of BMPs to separate and then recover PM, TP and TN. Results of this study as illustrated in the example given indicate that street sweeping (cleaning) practices using a variety of existing street sweeping technologies is significantly more economical than BMPs for PM, TP and TN. This example relates solid-phase (PM) separation and recovery for TP and TN for rainfall-runoff loadings given that BMP designs are primary runoff-based; where street sweeping recovers PM, TP and TN before interactions with urban drainage.

\section{ACKNOWLEDGEMENTS}

Florida Stormwater Association (FSA) and Florida Department of Environmental Protection (FDEP). A full detailed report of this study is given in [20].

\section{REFERENCES}

[1] Correll, D.L., The role of phosphorus in the eutrophication of receiving waters: A review. Journal of Environmental Quality, 27, pp. 261-266, 1998.

[2] Wendt, R.C. \& Corey, R.B., Phosphorus variations in surface runoff from agricultural lands as a function of land use. Journal of Environmental Quality, 9(1), pp. 130-136, 1980.

[3] Welch, E.B., Ecological Effects of Wastewater, 2nd ed., Chapman \& Hall: New York, 1992. 
[4] Sharpley, A.N., Daniel, T., Sims, J.T., Lemunyon, J., Stevens, R. \& Parry, R., Agricultural Phosphorus and Eutrophication, U.S. Department of Agriculture, U.S. GPO: Washington, DC, 1999.

[5] Dean, C.M., Sansalone, J.J., Cartledge, F.K. \& Pardue, J.H., Influence of hydrology on rainfall-runoff metal element speciation. Journal of Environmental Engineering, 131(4), pp. 632-642, 2005.

[6] Berretta, C. \& Sansalone, J., Hydrologic transport and partitioning of phosphorus fractions. Journal of Hydrology, 403, pp. 25-36, 2011.

[7] USEPA, National water quality inventory - 1988 report to congress, USEPA 440-490003, 1990.

[8] Duda, A.M., Addressing nonpoint sources of water pollution must become an international priority. Water Sci. Technol., 28(33), pp. 1-11, 1993.

[9] Brezonik, P.L. \& Stadelmann, T.H., Analysis and predictive models of stormwater runoff volumes, loads, and pollutants concentrations from watersheds in the Twin Cities metropolitan area, Minnesota, USA. Water Res., 36, pp. 1743-1757, 2002.

[10] Smith, M.K. et al., Perinatal toxicity associated with nickel chloride exposure. Environmental Research, 61, pp. 200-211, 1993.

[11] Ahn, J.H., Grant, S.B., Surbeck, C.Q., Digiacomo, P.M., Nezlin, N.P. \& Jiang, S., Coastal water quality impact of stormwater runoff from an urban watershed in southern California. Environmental Science \& Technology, 39(16), pp. 5940-5953, 2005.

[12] Pretty, J.N., Mason, C.F., Nedwell, D.B., Hine, R.E., Leaf, S. \& Dils, R., Environmental costs of freshwater eutrophication in England and Wales. Environmental Science \& Technology, 37, pp. 201-208, 2003.

[13] Sansalone, J. \& Ma, J., Parametric analysis and breakthrough modeling of phosphorus from Al-oxide filter media. Journal of Environmental Engineering, 137(2), pp. 108118, 2011.

[14] Ma, J., Ying, G. \& Sansalone, J., Transport and distribution of particulate matter phosphorus fractions in rainfall-runoff from roadway source areas. Journal of Environmental Engineering, 136(11), pp. 1197-1205, 2010.

[15] Kim, J.-Y., Ma, J., Howerter, K., Garofalo, G. \& Sansalone, J.J., Interactions of phosphorus with anthropogenic and engineered particulate matter as a function of mass, number and surface area. Urban Water Systems, Monograph 11, ed. W. James, CHI Publications: Guelph, Ontario, 20 pp., 2007.

[16] Liu, B., Ying, G. \& Sansalone, J., Volumetric filtration of rainfall runoff. I: eventbased separation of particulate matter. Journal of Environmental Engineering, 136(12), pp. 1321-1330, 2010.

[17] Sansalone, J., Liu, B. \& Ying, G., Volumetric filtration of rainfall runoff. II: eventbased and interevent nutrient fate. Journal of Environmental Engineering, 136(12), pp. 1331-1340, 2010.

[18] Sansalone, J.J. \& Cristina, C.M., Prediction of gradation-based heavy metal mass using granulometric indices of snowmelt particles. Journal of Environmental Engineering, 130(12), pp. 1488-1497, 2004.

[19] Dickenson, J. \& Sansalone, J., Discrete phase model representation of particulate matter (PM) for simulating PM separation by hydrodynamic unit operations. Environmental Science and Technology, 43(21), pp. 8220-8226, 2009.

[20] Sansalone, J., Berretta, C. \& Raje, S., Quantifying Nutrient Loads Associated with Urban Particulate Matter (PM) and Biogenic/Litter Recovery through Current MS4 Source Control and Maintenance Practices. Final Report to Florida Stormwater Association, 69 pp., May 2011. 